\title{
Erratum to: Body matters: rethinking the ethical acceptability of non-beneficial clinical research with children
}

\author{
Eva De Clercq • Domnita Oana Badarau •
}

Katharina M. Ruhe $\cdot$ Tenzin Wangmo

Published online: 20 December 2014

(C) Springer Science+Business Media Dordrecht 2014

\section{Erratum to: Med Health Care and Philos}

\section{DOI 10.1007/s11019-014-9616-3}

The authors forgot to add in the Acknowledgments the financial supporters.

Acknowledgments The authors acknowledge the financial support provided by the Swiss National Science Foundation (SNF NRP-67 Grant Number 406740 139283/1) and the Botnar Grant of the University of Basel. This article was conceptualized and designed as part of a study on children's end-of-life decision making funded through SNF's National Research Program (NRP)-67.

The online version of the original article can be found under doi:10.1007/s11019-014-9616-3.

E. De Clercq $(\bowtie) \cdot$ D. O. Badarau · K. M. Ruhe · T. Wangmo Institute for Biomedical Ethics, University of Basel, Bernoullistr 28, 4056 Basel, Switzerland

e-mail: eva.declercq@unibas.ch

D. O. Badarau

e-mail: Domnita.badarau@unibas.ch

K. M. Ruhe

e-mail: Katharina.ruhe@unibas.ch

T. Wangmo

e-mail: tenzin.wangmo@unibas.ch 